\title{
Modeling the reproductive impact of aquaculture-produced sexually fertile triploids on conspecific diploid populations
}

\author{
Federico M. Winkler ${ }^{1,2,3, *}$, Miguel Concha ${ }^{4}$, Christopher Concha ${ }^{1}$ \\ ${ }^{1}$ Departamento de Biología Marina, Facultad de Ciencias del Mar, Universidad Católica del Norte, Larrondo 1281, \\ Coquimbo 1780000, Chile \\ ${ }^{2}$ Centro de Estudios Avanzados en Zonas Áridas (CEAZA), Larrondo 1281, Coquimbo 1780000, Chile \\ ${ }^{3}$ Centro de Innovación Acuícola AquaPacífico, Universidad Católica del Norte, Larrondo 1281, Coquimbo 1780000, Chile \\ ${ }^{4}$ Departamento de Física, Liceo Bicentenario Alejandro Álvarez Jofre, Victoria 150, Ovalle 1840000, Chile
}

\begin{abstract}
The use of artificially produced triploid (3n) organisms has been proposed as a strategy to produce total or partial sterility in a number of species in order to prevent the potential negative effects of escapees on the genetic structure and integrity of wild conspecific populations or to avoid having alien species become feral in a new environment. When infertility is incomplete, triploid organisms are able to produce gametes that compete with those produced by wild diploid populations or crops that share the same habitat during reproductive periods, which may adversely affect the reproductive success of the wild population. In the present study, a model was developed in order to estimate the effects of the production of gametes by triploid organisms on the reproductive efficiency of a sympatric diploid population of the same species. The chance of the production of balanced gametes by triploids rapidly reduced with the increase of haploid number of the species. It was concluded that, in most aquatic species, this effect depends on the relative contribution of gametes derived from triploid individuals $\left(p_{e t}\right)$, which is determined by the proportion of triploids in the population and their relative fecundity relative to normal diploids. The variation of the reproductive efficiency in a mixed population of diploids and triploids will be directly proportional to $p_{e t}$ if only one sex is fertile in triploids but will have a logarithmic relationship if both sexes are fertile.
\end{abstract}

KEY WORDS: Triploids - Risk assessment $\cdot$ Reproductive success $\cdot$ Sterility $\cdot$ Chromosome manipulation $\cdot$ Fecundity

\section{INTRODUCTION}

Domesticated aquaculture species represent an environmental threat in different ways. The most cited concerns involve the risks that escapes represent from an ecological and socioeconomic point of view (Buschmann et al. 2006, Primavera 2006, ToledoGuedes et al. 2014, Edwards 2015, Clavelle et al. 2019, Rennie et al. 2019). However, escapes of domesticated strains of farmed aquatic species can also have a negative impact on the genetic structure and in-

*Corresponding author: fwinkler@ucn.cl tegrity of wild conspecific populations (Skaala et al. 1990, 1996, Arnaud-Haond et al. 2004, Naylor et al. 2005, Bekkevold et al. 2006, Glover et al. 2017), affecting their genetic diversity and long-term viability as a consequence of genetic introgression and potential loss of genetic variability and adaptations to wild conditions (McGinnity et al. 2003, Arnaud-Haond et al. 2004). The use of triploid organisms, i.e. those having 3 chromosome complements, has been proposed to prevent interbreeding of farmed and wild conspecifics (Guo \& Allen 1994a, Allen et al. 1999, Yeates et al.

(C) The authors 2019. Open Access under Creative Commons by Attribution Licence. Use, distribution and reproduction are unrestricted. Authors and original publication must be credited. 
2014) or to control escapes of genetically modified organisms (GMOs) (Hew \& Fletcher 2001). The presence of 3 homologous chromosomes sets interferes with the correct pairing and segregation of the chromosomes in meiosis, impairing normal gametogenesis and causing total or partial sterility (Allen \& Downing 1986, Purdom 1993) or producing unviable offspring (Lincoln 1981, Wong \& Zohar 2015). Triploids have been used in several fish and shellfish species and are widely used in aquaculture (Beaumont \& Fairbrother 1991, Beaumont et al. 1995, Maldonado et al. 2003, Arai 2001, Brake et al. 2004, Maldonado-Amparo et al. 2004, Piferrer et al. 2009, Fjelldal \& Hansen 2010) because their sexual sterility prevents or reduces the expression of traits related to sexual maturation and reproduction that are unfavorable to aquaculture production (Allen \& Downing 1986).

Experimental results from studies on fish species, such as carp Cyprinus carpio, have shown that triploids may or may not have partial gonadal development, with gonads showing little or no development (Gervai et al. 1980, Siraj et al. 1993). In females of some species of catfish (Ictalurus punctatus) and sole (Pleuronectes platessa and Platichthys flesus), although triploid females have gonads that are substantially smaller than the diploids, oocyte development has been observed (Lincoln 1981, Wolters et al. 1982). In triploid females of Cobitis taenia, gonadal development and ovules capable of undergoing fertilization have been observed (Juchno \& Boron 2010). In some fish species (Misgurnus anguillicaudatus, I. punctatus, P. platessa and P. flesus), triploid females show complete sterility and no observable gonadal development (Lincoln 1981, Wolters et al. 1982, Momotani et al. 2002), but males develop gonads similar in shape and size to normal diploid individuals, manifest secondary sexual characteristics, and produce sperm able to fertilize eggs leading to embryos that die within a short period of time (Lincoln 1981, Lozano et al. 1987).

In mollusks, triploidy may or may not produce complete sterility, depending on the species or larger taxonomic group (Allen \& Downing 1986, Komaru \& Wada 1989, Brake et al. 2004). Cytofluorometry studies in Pacific oyster Crassostrea gigas have shown that triploid males can produce aneuploid gametes, i.e. they do not present an exact multiple chromosome complement of the species (Allen 1987, 1988, Dheilly et al. 2014), and both males and females can release gametes with fertilization capabilities (Garnier-Géré et al. 2002, Normand et al. 2008). Triploid males of the freshwater snail Potamopyrgus antipodarum produce spermatozoa of normal appearance, but most of them are aneuploids (Soper et al. 2013). For example, despite the delay of gonadal development in oysters, male and female spawning triploids have been observed (Allen 1988, Allen \& Downing 1990) with gametes fully capable of fertilization, although the resulting progeny are aneuploid and therefore unviable (Guo \& Allen 1994a). In the pectinid Placopecten magellanicus, the males show total sterility, whereas the females can produce functional oocytes. Their fertilization with spermatozoa of diploid males, however, generates mainly aneuploid larvae that die within the first $7 \mathrm{~d}$ after fertilization (Meng et al. 2012). In all cases where absence of sterility has been observed, however, there is some degree of reduction of gonadogenesis, which is usually more pronounced in males than in females (Allen \& Downing 1986, Allen 1987, 1988).

In species where triploid sterility is incomplete, gametes can be released and produce non-viable progeny (Lozano et al. 1987, Guo \& Allen 1994a, Momotani et al. 2002, Meng et al. 2012, Hamasaki et al. 2013) or offspring with varying degrees of aneuploidy (He et al. 2004). If one or both sexes in a triploid population produce functional gametes, they could interfere with the normal reproductive process in a conspecific diploid population that shares the same habitat. This would be attributable, primarily, to the probability of fusion of normal haploid gametes of the wild population with aneuploid gametes produced by the triploid individuals. Therefore, it is necessary to develop tools that allow us to quantify the environmental risks associated with the introduction of partially sterile triploid individuals with diploid populations of the same species. In the present study, we derived a model that allows the estimation of this impact and carried out a simulation of the consequences in a hypothetical species.

\section{THE MODEL}

During meiosis, pairs of homologous chromosomes segregate independently of each other, allowing genetic recombination by chromosomal permutation. In diploid species, assuming that each chromosome of the homologous pair of a complement of one individual may be distinguished, $2^{n}$ different haploid gametes will be produced, $n$ being the haploid number of chromosomes in a particular species. In a hypothetical triploid individual, if all the single chromosomes pass to the same pole and the other 2 chromosomes simultaneously pass to the opposite pole in meiosis I, the gametes that are produced will be hap- 
loid and diploid. The probability of this type of meiosis, which is likely to be low, will be $(1 / 2)^{n-1}$, which is the proportion of the total gametes produced that will be chromosomally balanced, half of which will be haploid and the other half diploid, i.e.:

$$
k=(1 / 2)^{n}
$$

gametes of each of these categories, where $k$ is the frequency of chromosomally balanced gametes (haploids or diploids). They will also produce gametes which will carry chromosome numbers intermediate between the haploid and diploid number (aneuploids) as the remaining fraction, 1 :

$$
l=1-(1 / 2)^{n-1}
$$

Thus, the proportion of aneuploid gametes produced by a triploid individual depends on the $n$ of the species (Fig. 1). With $n=10$, less than $0.2 \%$ of the gametes produced would be chromosomally balanced; half of them diploid and half haploid.

In a population in which all individuals are triploid, with both sexes fertile, the frequencies of different types of zygotes (diploid, aneuploid, triploid) produced in a reproductive event will be:

$$
(2 k+1)^{2}=1
$$

where $k$ is the frequency of the haploid and diploid gametes and $l$ is frequency of the aneuploid gametes, respectively.

In a mixed population of diploid and triploid organisms, the impact of triploids on the overall reproductive success of the population will depend on their ability to contribute functional gametes to the reproductive process. In different groups of organisms, fertile triploid individuals have shown lower levels of fertility than their conspecific diploids (Guo \& Allen 1994b, Jouaux et al. 2010, Meng et al. 2012, Zhao et

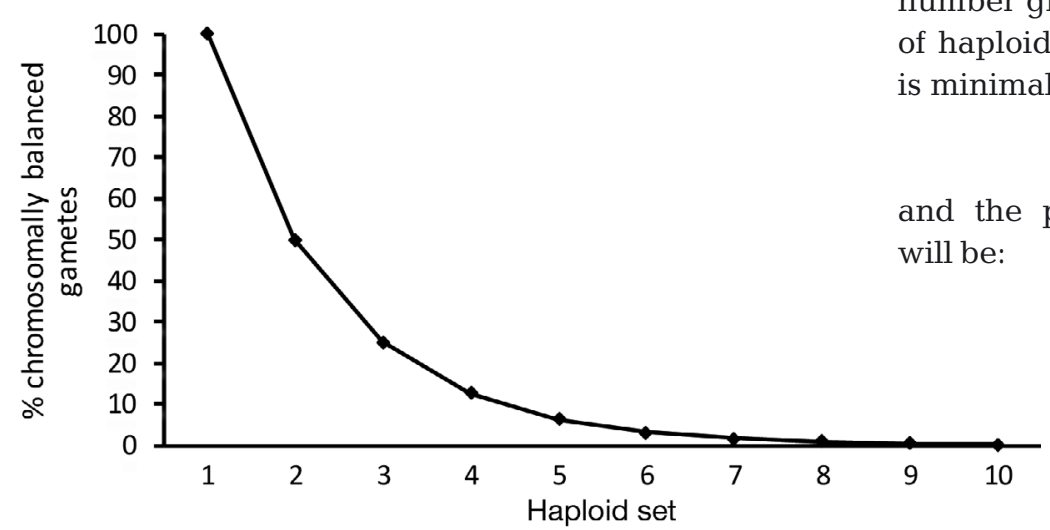

Fig. 1. Proportion of chromosomally balanced gametes (haploid and diploid) produced by triploid individuals as a function of the haploid number of the species al. 2014). Thus, the effect of the triploids will be determined by the proportion they represent in the population $(t)$ and their fecundity relative to that of the normal diploids $\left(f_{t}\right)$. Indeed, the relative gamete contribution of the triploids $\left(p_{e t}\right)$ to the reproductive process in a mixed population will be:

$$
p_{e t}=t \times f_{t}
$$

This is assuming that triploids have an equal sexual proportion, and that both sexes have the same fecundity.

Based on Eq. (3) and under random mating, it can be inferred that the frequency of different types of gametes in a mixed diploid and triploid population will be:

$$
p_{e t}(2 k+1)+p_{e d}=1
$$

where $p_{e d}$ is the relative gamete contribution of diploids, which exclusively provide haploid gametes. Then, rearranging the terms:

$$
2 p_{e t} k+p_{e t} l+p_{e d}=1
$$

the proportion of haploid gametes, $H$, is:

$$
H=p_{e t} k+p_{e d}
$$

The different types of zygotes will be formed with frequencies:

$$
\left(H+p_{e t} k+p_{e t} l\right)^{2}=1
$$

That is to say, $H^{2}$ diploids, $\left(p_{e t} k\right)^{2}$ tetraploids, $2 H p_{e t} k$ triploids and $\left.\left(p_{e t}^{2} l^{2}\right)^{2}+2 H p_{e t} l+p_{e t}^{2} 2 k l\right)$ aneuploids. The latter would generally be unviable or suffer serious functional impairment during development.

Given that $p_{e d}=1-p_{e t}, H$ takes the form:

$$
H=1+p_{e t}\left((1 / 2)^{n}-1\right)
$$

As can be seen in Fig. 1, in a species with a diploid number greater than 6 chromosomes, the proportion of haploid gametes produced by triploid individuals is minimal, such that Eq. (9) can be approximated to:

$$
H \approx 1-p_{e t}
$$

and the proportion of normal diploid zygotes, $D$, will be:

$$
D \approx\left(1-p_{e t}\right)^{2}
$$

In other words, if the percentage of triploids and their relative fecundity are known in a population with random reproduction, the impact of the introduction of these triploids on the reproductive efficiency of the wild diploid population with which they interact can be estimated. 
If each sex is at a different frequency in the population, or if the sexes differ in fecundity relative to the diploids, the relative contribution of the gametes of the females $\left(p_{\text {etd }}\right)$ and males $\left(p_{\text {ets }}\right)$ in the reproductive process will be, for females:

$$
p_{\text {etd }}=t_{d} \times f_{t d}
$$

and for males:

$$
p_{\text {ets }} \approx t_{s} \times f_{t s}
$$

where $t_{d}$ and $t_{s}$ are the proportions of female and male triploids in the population, respectively, and $f_{t d}$ and $f_{t s}$ are the respective relative fecundities. If female triploids show null gonadal development, as observed in some species of fish, their relative contribution of gametes during the reproductive process in a mixed population is $p_{\text {etd }}=0$. Thus, the frequency of female diploid gametes is $k_{d}=1$, and that of haploid sperm will be $k_{s} \approx 1-p_{\text {ets }}$. Therefore, the proportion of normal diploid zygotes will be:

$$
D \approx k_{d} \times k_{s} \approx 1-p_{\text {ets }}
$$

That is, the effect of the presence of triploid males on the average biological fitness of the population will be directly proportional to their gametic contribution during reproduction.

\section{DISCUSSION}

The haploid number of chromosomes that have been described for different species of Actinopterygii fish typically ranges from 22 to 250 , with most of the species to displaying 48 or 50 chromosomes (Mank \& Avise 2006). In mollusks, the number of haploid chromosomes varies between 6 and 52 for different species (Thiriot-Quievreux 1994). On the basis of Eq. (1), it can be estimated that in a fertile triploid population of a species with a haploid number of $n=10$, as in most oyster species (Nakamura 1985), the frequency of haploid gametes will be

$$
k=(1 / 2)^{10}=9.76 \times 10^{-4}
$$

such that $H^{2}$ (Eq. 9) of the zygotes will be diploids. From this, it can be inferred that the use of triploids in species with diploid number $2 n \geq 20$ has a low probability of producing viable offspring because the number of chromosomally balanced gametes is negatively correlated with the haploid number of chromosomes (Fig. 1). However, given the high fecundity observed in many mollusk species, it is likely that some normal diploid zygotes will be randomly generated. If, as usually occurs in fish species, females do not develop gonads and are completely sterile, the use of $100 \%$ triploid populations would be a good strategy to minimize the risks if an introduced species became feral due to escape from fish farms (Kerby et al. 2002 Taylor et al. 2012, Yeates et al. 2014). However, it is necessary to study every species individually, since, in triploid individuals of the ornamental carp koi Cyprinus carpio, females with gonadal development and egg production have been observed (Gomelsky et al. 2015).

In diploid farmed salmon in Norway, it has been observed that the frequency of spontaneous triploids is as low as $2 \%$, and that the frequency of triploids in fish escaped from cages does not exceed $1 \%$ (Glover et al. 2015). It has been hypothesized that the release of triploid fish in natural ecosystems will likely have lower ecological and genetic impacts than the release of their domesticated diploid congeners. For example, triploid Atlantic salmon Salmo salar released into the natural environment are able to return to their native birth place, but at a lesser proportion than their diploid congeners (Cotter et al. 2000). This, coupled with its low fertility, reduces the probability of miscegenation. Thus, triploidization alone, or combined with the use of mono sex populations, could significantly decrease the effects of farmed fish on wild populations (Piferrer et al. 2009).

However, triploid Atlantic salmon males exhibit reproductive behaviors similar to that of their diploid congeners and are able to stimulate spawning in diploid females (Fjelldal et al. 2014). Moreover, some autotriploid male fishes can produce aneuploid spermatozoa capable of activating oocytes. Studies in triploid koi carp have demonstrated not only that triploid females can develop their gonads almost identically to diploid females, but are also able to produce viable offspring with diploid and aneuploid genotypes (Gomelsky et al. 2015). Therefore, the risk of escape and colonization using triploids of an alien species would come mainly from the presence of diploid organisms in a supposedly all triploid population, the existence of heteroploid mosaic individuals (Allen et al. 1999), or the presence of triploids capable of producing viable zygotes.

Taking the above into account, and assuming that fertilization occurs at random, from Eq. (8) it can be inferred that the reproductive efficiency of a diploid/ triploid mixed population would decrease as a function of $p_{\text {et }}$. Fig. 2 illustrates the expected increase in chromosomally imbalanced zygotes with the increase in $p_{\text {et }}$ in a population with $n=10$, with both sexes fertile and random fertilization. If $p_{e t}>0.9$, the proportion of normal diploid zygotes in the progeny 


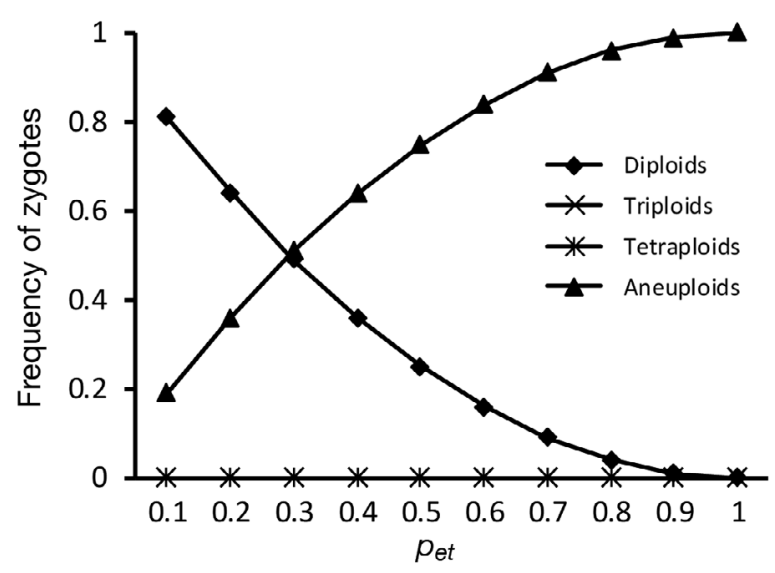

Fig. 2. Expected frequency of diploids, aneuploids, triploids and tetraploid zygotes of a species with $n=10$ as a function of the relative contribution of triploids $\left(p_{e t}\right)$. Fertilization is assumed to be random, with equal fecundity for both kinds of karyotype

will be $<1 \%$. This figure does not vary markedly between hypothetical species with half or twice the number of chromosomes used in the example. The frequency of triploid and tetraploid zygotes, on the other hand, is negligible $\left(<2.9 \times 10^{-6}\right)$, and, although these individuals are likely to be viable, their progeny will have little chance of surviving or producing viable offspring. Consistent with this prediction, the reproduction of triploid females of Patinopecten yessoensis with diploid males can produce offspring with a viability of $4 \times 10^{-6} \%$ lower than crosses between diploid individuals (Meng et al. 2012).

Furthermore, it is evident that the figure resulting from the application of Eq. (11) (Fig. 3; fertile triploid males and females) does not show significant differences compared to those obtained with Eq. (8). Therefore, it is possible to use the latter as a reasonable approximation to estimate the possible impact of fertile triploids on the relative fecundity of a mixed diploid/triploid population.

If only one of the triploid sexes is fertile, the impact of their introduction on the overall reproductive success of the receiving diploid population will be directly proportional to $p_{e t}$ during the reproductive process (Fig. 3). When triploids of both sexes have different relative contributions of gametes, $D$ will vary within the area between the 2 curves indicated in Fig. 3. If haploid and aneuploid gametes have different fertilization capabilities, the curves in Fig. 3 will have a different shape and the magnitude of those differences can be estimated based on the bias in comparison with the model. Until this study, there was little information in the literature about the relative fertilization capacity of triploid gametes vs. gametes produced by diploids. This could be mean-

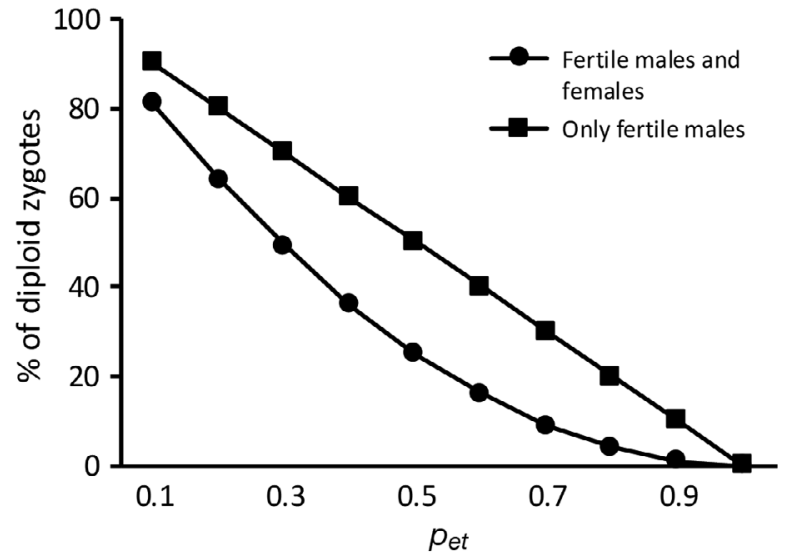

Fig. 3. Proportion of diploid zygotes produced in a mixed population of diploid and triploid brooders with one or both triploid sexes fertile, as a function of the relative contribution of triploids $\left(p_{\text {et }}\right)$

ingful information, because if the gametes' ploidy affects the relative fertilization capacity, the potential impact of fertile triploids on the reproductive success of a diploid population could be lower or greater than what the model predicts.

In the Pacific oyster Crassostrea gigas, triploids present gonadal development that is more delayed than the diploids (Nell 2002) and are less fertile, with 41 to $46 \%$ and 20 to $26 \%$ lower fecundity in females and males, respectively (Guo \& Allen 1994b, Gong et al. 2004, Normand et al. 2008, Jouaux et al. 2010). The sex ratio in triploids of this species is about 1.6:1 males to females, similar to that observed in normal diploid populations (Allen 1987). Thus, the relative fecundity of a mixed population containing $90 \%$ triploids in this species will be approximately $10 \%$ lower than that of a population formed only by diploids (Fig. 4).

Thus, the proposed model is able to offer a quantitative estimation of the possible impact of the intro-

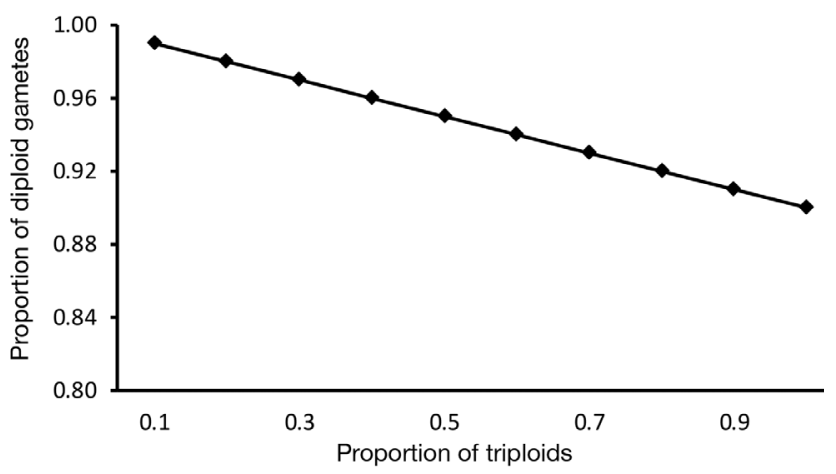

Fig. 4. Frequency of diploid zygotes expected in a population of Pacific oysters Crassostrea gigas $(2 n=20)$ with different relative fecundities between males and females as a function of the proportion of triploids 
duction of triploid organisms on the reproductive success of a wild diploid population. Simulations suggest that the reduction in fecundity of the wild diploid population due to unbalanced gametes produced by triploids could be very small if their fecundity or their proportion in the spawning population is low. However, the evaluation could be somewhat more complex in the case of fish, as their reproductive behavior may play a relevant role in the fitness of the individual as well as in the overall fecundity of a mixed population. Moreover, the model can be used to evaluate if euploid and aneuploid gametes have similar relative fecundation capacities.

In a scenario of increasing aquaculture production, it is important to have a more objective vision of the potential effects of triploid organisms on natural populations and their use as a strategy to control the spread of alien species in new environments. As a corollary, our results suggest that partially fertile triploids could be used to control alien species' populations due to their potentially negative reproductive effects; the model presented here allows us to determine the optimal conditions under which such a scenario would be successful.

Acknowledgements. The authors thank Vicenta Valdivia for her valuable review of the English version of the manuscript.

\section{LITERATURE CITED}

Allen SK Jr (1987) Gametogenesis in three species of triploid shellfish: Mya arenaria, Crassostrea gigas and Crassostrea virginica. In: Tiews K (eds) Selection, hybridization and genetic engineering in aquaculture of fish and shellfish for consumption and stocking, Vol 2. H Heenemann \& Co, Berlin, p 207-217

Allen SK Jr (1988) Triploid oysters ensure year-round supply. Oceanus 31:58-63

Allen SK Jr, Downing SL (1986) Performance of triploid Pacific oysters, Crassostrea gigas (Thunberg). I. Survival, growth, glycogen content, and sexual maturation in yearlings. J Exp Mar Biol Ecol 102:197-208

Allen SK Jr, Downing SL (1990) Performance of triploid Pacific oysters, Crassostrea gigas: gametogenesis. Can J Fish Aquat Sci 47:1213-1222

Allen SK Jr, Howe A, Gallivan T, Guo X, DeBrosse G (1999) Genotype and environmental variation in reversion of triploid Crassostrea gigas to the heteroploid mosaic state. J Shellfish Res 18:293

Arai K (2001) Genetic improvement of aquaculture finfish species by chromosome manipulation techniques in Japan. Aquaculture 197:205-228

Arnaud-Haond S, Vonau V, Bonhomme F, Boudry P and others (2004) Spatio-temporal variation in the genetic composition of wild populations of pearl oyster (Pinctada margaritifera cumingii) in French Polynesia following 10 years of juvenile translocation. Mol Ecol 13:2001-2007
Beaumont A, Fairbrother J (1991) Ploidy manipulation in molluscan shellfish: a review. J Shellfish Res 10:1-18

* Beaumont A, Fairbrother J, Hoare K (1995) Multilocus heterozygosity and size: a test of hypotheses using triploid Mytilus edulis. Heredity 75:256-266

Bekkevold D, Hansen MM, Nielsen EE (2006) Genetic impact of gadoid culture on wild fish populations: predictions, lessons from salmonids, and possibilities for minimizing adverse effects. ICES J Mar Sci 63:198-208

* Brake J, Davidson J, Davis J (2004) Field observations on growth, gametogenesis, and sex ratio of triploid and diploid Mytilus edulis. Aquaculture 236:179-191

*Buschmann AH, Riquelme VA, Hernández-González MC, Varela D and others (2006) A review of the impacts of salmonid farming on marine coastal ecosystems in the southeast Pacific. ICES J Mar Sci 63:1338-1345

* Clavelle T, Lester SE, Gentry R, Froehlich HE (2019) Interactions and management for the future of marine aquaculture and capture fisheries. Fish Fish 20:368-388

* Cotter D, O'Donovan V, O'Maoiléidigh N, Rogan G, Roche N, Wilkins NP (2000) An evaluation of the use of triploid Atlantic salmon (Salmo salar L.) in minimizing the impact of escaped farmed salmon on wild populations. Aquaculture 186:61-75

*Dheilly NM, Jouaux A, Boudry P, Favrel P, Lelong C (2014) Transcriptomic profiling of gametogenesis in triploid pacific oyster Crassostrea gigas: towards an understanding of partial sterility associated with triploidy. PLOS ONE 9:e112094

Edwards P (2015) Aquaculture environment interactions: past, present and likely future trends. Aquaculture 447: $2-14$

Fjelldal P, Hansen T (2010) Vertebral deformities in triploid Atlantic salmon (Salmo salar L.) underyearling smolts. Aquaculture 309:131-136

Fjelldal P, Wennevik V, Fleming IA, Hansen T, Glover KA (2014) Triploid (sterile) farmed Atlantic salmon males attempt to spawn with wild females. Aquacult Environ Interact 5:155-162

* Garnier-Géré PH, Naciri-Graven Y, Bougrier S, Magoulas A and others (2002) Influences of triploidy, parentage and genetic diversity on growth of the Pacific oyster Crassostrea gigas reared in contrasting natural environments. Mol Ecol 11:1499-1514

*Gervai J, Peter S, Nagy A, Horvath L, Csanyi V (1980) Induced triploidy in carp, Cyprinus carpio L. J Fish Biol 17:667-671

Glover KA, Madhun AS, Dahle G, Sørvik AGE and others (2015) The frequency of spontaneous triploidy in farmed Atlantic salmon produced in Norway during the period 2007-2014. BMC Genet 16:37

* Glover KA, Solberg MF, McGinnity P, Hindar K and others (2017) Half a century of interaction between farmed and wild Atlantic salmon: summary of knowledge and unanswered questions. Fish Fish 18:890-927

*Gomelsky B, Schneider KJ, Anil A, Delomas TA (2015) Gonad development in triploid ornamental koi carp and results of crossing triploid females with diploid males. $\mathrm{N}$ Am J Aquaculture 77:96-101

* Gong N, Yang H, Zhang G, Landau BJ, Guo X (2004) Chromosome inheritance in triploid pacific oyster Crassostrea gigas Thunberg. Heredity 93:408-415

Guo X, Allen SK Jr (1994a) Reproductive potential and genetics of triploid Pacific, Crassostrea gigas (Thunberg). Biol Bull (Woods Hole) 187:309-318 
Guo X, Allen SK Jr (1994b) Sex determination and polyploid gigantism in the dwarf surfclam (Mulinia lateralis Say). Genetics 138:1199-1206

*Hamasaki M, Takeuchi Y, Miyaki K, Yoshizaki G (2013) Gonadal development and fertility of triploid grass puffer Takifugu niphobles induced by cold shock treatment. Mar Biotechnol (NY) 15:133-144

* He M, Jiang W, Huang L (2004) Studies on aneuploid pearl oyster (Pinctada martensii Dunker) produced by crossing triploid females and a diploid male following the inhibition of PB1. Aquaculture 230:117-124

Hew CL, Fletcher GL (2001) The role of aquatic biotechnology in aquaculture. Aquaculture 197:191-204

Jouaux A, Heude-Berthelin C, Sourdaine P, Mathieu M, Kellner K (2010) Gametogenic stages in triploid oysters Crassostrea gigas: irregular locking of gonial proliferation and subsequent reproductive effort. J Exp Mar Biol Ecol 395:162-170

Juchno D, Boron A (2010) Fecundity of the spined loach, Cobitis taenia (Pisces, Cobitidae) and natural allopolyploids of Cobitis from a diploid-polyploid population. Folia Zool (Brno) 59:35-43

Kerby J, Everson J, Harrell R, Geiger J, Starling C, Revels H (2002) Performance comparisons between diploid and triploid sunshine bass in fresh water ponds. Aquaculture 211:91-108

Komaru A, Wada KT (1989) Gametogenesis and growth of induced triploid scallops Chlamys nobilis. Nippon Suisan Gakk 55:447-452 (in Japanese with English Abstract)

Lincoln RF (1981) Sexual maturation in female triploid plaice, Pleuronectes platessa, and plaice $\times$ flounder, Platichthys flesus, hybrids. J Fish Biol 19:499-507

Lozano R, Rejon CR, Ruiz M (1987) Manipulación cromosómica en organismos acuáticos. In: Espinosa de los Monteros J, Labarta U (eds) Genética en acuicultura. Mundi-Prensa Libros, Madrid, p 215-246

*Maldonado R, Ibarra A, Ramírez J (2003) Inducción a la tetraploidía en almeja catarina, Argopecten ventricosus (Sowerby II, 1842). Cienc Mar 29:229-238

* Maldonado-Amparo R, Ramírez J, Ávila S, Ibarra AM (2004) Triploid lion-paw scallop (Nodipecten subnodosus); growth, gametogenesis, and gametic cell frequencies when grown at a high food availability site. Aquaculture 235:185-205

Mank JE, Avise JC (2006) Phylogenetic conservation of chromosome numbers in Actinopterygiian fishes. Genetica 127:321-327

McGinnity P, Prodöhl P, Ferguson A, Hynes R and others (2003) Fitness reduction and potential extinction of wild populations of Atlantic salmon, Salmo salar, as a result of interactions with escaped farm salmon. Proc Biol Sci 270: 2443-2450

Meng Q, Bao Z, Wang Z, Wang S, Hu J, Hu X, Huang X (2012) Growth and reproductive performance of triploid yesso scallops (Patinopecten yessoensis) induced by hypotonic shock. J Shellfish Res 31:1113-1122

Momotani S, Morishima K, Zhang Q, Arai K (2002) Genetic analyses of the progeny of triploid gynogens induced from unreduced eggs of triploid (diploid female $\times$ tetraploid male) loach. Aquaculture 204:311-322

Nakamura HK (1985) A review of molluscan cytogenetic information based on the CISMOCH-computerized index system for molluscan chromosomes. Bivalvia, Polyplacophora and Cephalopod. Venus 44:193-226

Naylor R, Hindar K, Fleming IA, Goldburg R and others
(2005) Fugitive salmon: assessing the risks of escaped fish from net-pen aquaculture. Bioscience 55:427-437

Nell JA (2002) Farming triploid oysters. Aquaculture 210: 69-88

Normand J, Le Pecnnec M, Boudry P (2008) Comparative histological study of gametogenesis in diploid and triploid pacific oysters (Crassostrea gigas) reared in an estuarine farming site in France during the 2003 heatwave. Aquaculture 282:124-129

* Piferrer F, Beaumont A, Falguière J, Flajšhans M, Haffray P, Colombo L (2009) Polyploid fish and shellfish: production, biology and applications to aquaculture for performance improvement and genetic containment. Aquaculture 293:125-156

* Primavera JH (2006) Overcoming the impacts of aquaculture on the coastal zone. Ocean Coast Manage 49: $531-545$

Purdom CE (1993) Chromosome engineering. In: Purdom CE (ed) Genetics and fish breeding. Chapman \& Hall, London, p 204-222

Rennie MD, Kennedy P, Mills KH, Rodgers CMC and others (2019) Impacts of freshwater aquaculture on fish communities: a whole-ecosystem experimental approach. Freshw Biol 64:870-885

Siraj S, Daud S, Ang K (1993) Growth performance and gonad development in diploid and triploid Clarias batrachus (Linnaeus). Pertanika J Trop Agric Sci 16:167-171

Skaala Ø, Dahle G, Jørstad KE, Nævdal G (1990) Interactions between natural and farmed fish populations: information from genetic markers. J Fish Biol 36:449-460

* Skaala Ø, Jørstad KE, Borgstrøm R (1996) Genetic impact on two wild brown trout (Salmo trutta) populations after release of non-indigenous hatchery spawners. Can J Fish Aquat Sci 53:2027-2035

* Soper DM, Neiman M, Savytskyy OP, Zolan ME, Lively CM (2013) Spermatozoa production by triploid males in the New Zealand freshwater snail Potamopyrgus antipodarum. Biol J Linn Soc Lond 110:227-234

* Taylor JF, Leclercq E, Preston AC, Guy D, Migaud H (2012) Parr-smolt transformation in out-of-season triploid Atlantic salmon (Salmo salar L.). Aquaculture 362-363:255-263

Thiriot-Quievreux C (1994) Advances in cytogenetics of aquatic organism. In: Beaumont A (ed) Genetics and evolution of aquatic organisms. Chapman \& Hall, London, p 369-388

*Toledo-Guedes K, Sánchez-Jerez P, Benjumea ME, Brito A (2014) Farming-up coastal fish assemblages through a massive aquaculture escape event. Mar Environ Res 98: 86-95

*Wolters WR, Libey GS, Chrisman CL (1982) Effect of triploidy on growth and gonad development of channel catfish. Trans Am Fish Soc 111:102-105

*Wong TT, Zohar Y (2015) Production of reproductively sterile fish: a mini-review of germ cell elimination technologies. Gen Comp Endocrinol 221:3-8

*Yeates SE, Einum S, Fleming IA, Holt WV, Gage MJG (2014) Assessing risks of invasion through gamete performance: farm Atlantic salmon sperm and eggs show equivalence in function, fertility, compatibility and competitiveness to wild Atlantic salmon. Evol Appl 7:493-505

K Zhao Y, Saito T, Pšenička M, Fujimoto T, Arai K (2014) Comparison of spermatozoa parameters, fine structures, and energy-related factors among tetraploid, hypertetraploid, and hyper-triploid loaches (Misgurnus anguillicaudatus). J Exp Zool A Ecol Genet Physiol 321:198-206 